\title{
Entrepreneur Development Management Practices For Sustainable Service: Case Of BRAC Water, Sanitation And Hygiene Programme In Bangladesh
}

\author{
Md. Mahidul Islam, \\ Senior Sector Specialist (NRD Research), Research \& M\&E Unit of BRAC Water, Sanitation and Hygiene \\ (WASH) Programme, BRAC Centre, BRAC Head Office, 75 Mohakhali, Dhaka-1212, E- \\ mail:mhidul.i@brac.net,mahidul68@gmail.com,Contact:+8801912161600,Skype: mahi.dul,Bangladesh
}

\begin{abstract}
BRAC has made notable contributions in many sectors of human development since 1972.To meet the Millennium Development Goals) and Sustainable development Goals, BRAC has been implementing a Water, Sanitation and Hygiene programme with different donor supports which reached out to more than 66.4 million people in Bangladesh. This case study describes how BRAC WASH programme adopted different approaches to generate economic opportunities for the local sanitation entrepreneurs. Finding shows that in the beginning however, there were not enough entrepreneurs at right place with the right products. This created a challenge to meet the demand that the programme was stimulating. To meet the huge demand, BRAC supported the development of sanitation entrepreneurs covering issues of access, capacity building, technological development and innovation, price control, quality assurance, sources of finance, linkage with communities, supply chain and value chain development, integrated monitoring, advocacy and integrity of the service delivery system etc. The programme took a leading role in supporting around 3,600 sanitation entrepreneurs to establish their business. As result it has reached millions with hygienic latrine towards transforming lives to good health, gender equality, women's empowerment, poverty reduction and dignity. These lessons learned initiatives could inspire the underserved people in developing countries.
\end{abstract}

Keywords: Environmental Sustainability, Sanitation demand and supply, Social Entrepreneurship Development, Social Business, Supply Chain, Value Chain.

\section{Introduction}

Since 1972, BRAC has been working with the objectives of poverty alleviation and empowering the poor with a holistic approach. It has made notable contributions in the field of micro-finance, health, education, agriculture, environment, gender development and women's empowerment, enterprise development and multidimensional development activities. In order to contribute towards achieving the Millennium Development Goals (MDGs) and Sustainable Development Goals, BRAC has been implementing the Water, Sanitation and Hygiene (WASH) programme. The WASH programme of BRAC started in May 2006 in 150 sub-districts (Phase I).In 2011, it was extended to 25 sub-districts (Phase II), and mid 2012 expanded to 73 hard-to -reach areas (Phase-III), total 252 sub-districts and covering some 66.4 million people in half of Bangladesh. The financial support comes from different donor supports such as the Embassy of the Kingdom of the Netherlands (EKN), Bill \& Melinda Gates Foundation (BMGF), Strategic Partnership Agreement (SPA) by DFID and DFAT. In 2014, 'Charity Water' provided funding to work in 250 secondary schools in rural area and 'Splash', an international NGO based in Seattle, USA, provided support for 'Urban WASH in school' to provide safe water, sanitation and hygiene education among the poorest children in Dhaka and Chittagong cities. The programme aims to improve the health of poor and enhance equitable development through provision of sustainable and integrated WASH services in the rural areas of Bangladesh; inducing hygienic behaviours to break the contamination cycle of unsanitary latrines and contaminated water; and ensuring sustainability and scaling-up (Kabir et.al 2008). Inspiring and supporting people to construct or repair hygienic household latrines have been key aspects of the programme. At the beginning however, there were not enough entrepreneurs in the right place with the right products for people to access sanitary materials and to maintain facilities. This created a challenge to meet the demand that the programme was stimulating. The programme required innovative ways to develop local sanitation centres that could provide sanitation services at scale and support the initiatives that inspired millions of people in Bangladesh to install hygienic latrines.

\section{Conceptual clarification}

Five terms used in this paper in the context of market development need to be defined:

Demand: The needs and preference of consumers referring to the amount (quantity) of a product or service that people want. The demand is the amount of a product people are willing to buy at a certain price. 
Supply: The availability and accessibility of sanitation products and services that determine how much the market can make available. The quantity supplied refers to the amount of certain good products are willing to supply at a certain price.

Entrepreneurs: In this context, entrepreneurs manufacture and sell toilet hardware products like rings, slabs, pans, water seals etc. in rural and urban areas.

Water seal of latrine: A pour-flush latrine utilizes a water seal to prevent odour and insects entering the latrine from the pit. Water seal may be part of the pan unit or may be connected immediately below the pan. For on-site sanitation, flushing is normally carried out by the wash-down method where the force of the flush water thrown into the pan is enough to drive the excreta through the water seal (WHO, 1992; 246 pages).

Improved sanitation facilities: are likely to ensure hygienic separation of excreta from human contact. They include the following facilities:

- Flush/pour flush to: Piped sewer system, Septic tank, pit latrine

- Ventilated Improved Pit (VIP) latrine, Pit latrine with slab, Composting toilet

The facilities that are not shared or not public are considered improved (JMP, 2014, p-48).

\section{Objective of the study}

The objective of this paper is to describe how the BRAC WASH programme assessed sanitation demand at the beginning and how it developed local sanitation entrepreneurs. This paper also addresses how these entrepreneurs generate social business opportunities while contributing towards the national MDG target on sanitation in Bangladesh. The entrepreneurship development approaches adopted by BRAC WASH could help policy makers, practitioners, donor agencies, and multi-stakeholders in the WASH sector, who also aim to provide sanitation services in other developing countries.

\section{Research methodology}

The data were collected through empirical field experience i.e. frequent field visits and involvement of entrepreneur development process, knowledge sharing, supervision, note taking, interviewing with entrepreneurs and community interaction. Secondly, data were collected when programme measuring the performance of services. In addition, data were collected from the Management Information System (MIS) of WASH programme and Research and Evaluation Division (RED) of BRAC. Data were cross-checked and triangulated to ensure validity of information.

\subsection{Demand assessment on wash services}

\section{Study findings}

Demand assessment was very important for programme implementation. In 2007, BRAC WASH programme conducted a study on 'willingness to pay for improved sanitation' through the Research and Evaluation Division (RED), to provide insights into sanitation-related demand. The study indicated that about $80 \%$ of the households were willing to pay for improved sanitation services. It found that more than $90 \%$ of households preferred to pay by monthly instalments (Seraj, 2008). In addition to that, BRAC WASH and IRC (The Netherlands-based organisation), jointly conducted a study on 'Sanitation demand and supply chain in rural Bangladesh' in 2013/2014, to identify the main constraints and challenges including those existing in hard-to-reach areas of Bangladesh. This joint study addressed how rural sanitation marketing strategies can be designed that are based on a better understanding of household demand, potential and capacity of local entrepreneurs to supply products that respond to consumer needs and desires (Baetings et al, 2014). Many people, including the poor, are willing to pay for good sanitation that will satisfy their needs and desires if the products and services are affordable, packaged and marketed appropriately, and if they are accessible. Both research findings helped to identify actual demand in the community. The programme sought to generate sustained demand and at the same time ensured a cost-effective and appropriate service.

\subsection{Sanitation entrepreneur development management and practices}

The WASH sector cannot be sustainable without a high standard of materials. BRAC WASH has been raising awareness in the community for quality materials as well as developing capacity of rural sanitation entrepreneurs to raise standards (Islam, M. 2013). At the very beginning of the programme (May 2006), the accessibility of sanitary materials were insufficient and it was an enormous challenge to access sanitary construction materials in the working areas. The programme therefore made a major contribution to establishing 
around 3,600 local sanitation entrepreneurs in rural and peri-urban areas. The major entrepreneur's development management and practices approaches are as follows;

\subsubsection{Identified potential entrepreneurs and locations}

In the beginning of the programme, it was found that sanitation entrepreneurs were too far from their villages, and some areas were not any sanitation material production centre. They local people complained that they could not get required sanitary materials. It was found that there were no even potential individuals who could supply sanitary materials. The entrepreneurs who were existed, they were struggled with their businesses and hardly made profit. The sanitation coverage also low due to insufficient materials. To overcome this problem, the programme then identified vulnerable entrepreneurs and some enthusiastic individuals who could successfully run sanitation business. In addition to that, Village WASH Committees (VWC) member of WASH programme helped to select convenient locations to set up production centres.

\subsubsection{Capacity building and building capacity of entrepreneurs}

Capacity building is referred as the skills, knowledge, structures and ways of working that make them effective. Building capacity means developing further each of these, building on existing strengths, addressing gaps and weaknesses. It was observed that most of the local entrepreneurs did not have the knowledge for manufacturing sanitary hardware materials. For example, to build a standard toilet ring, it is required 10 Gauge 3 Master Sheet Wire and the ring surrounding would be 1.5 inches thickness, inner dais 27 inches and quarter 30 inches of overall layout. They could not able to maintain the accurate procedure i.e. constructing latrine Reinforced Cement Concrete (RCC,) squatting slab, ring, and pan and pit cover. So, the engineers of WASH programme along with sub assistant engineers of Department of Public Health Engineering (DPHE) conducted two days in each working Upazila. In addition, entrepreneurs received planning and financial management orientation. A total of 3,608 entrepreneurs received these capacity building training and orientations by different sessions in each working Upazila.

\subsubsection{Technological options, innovation and prices}

In programme areas, toilets technology has gradually improved and several designs have been implemented around the country to suit geographical context and individual choice. The programme developed twin pit latrines that make sustainable sludge management, and floating latrine for water logged areas. The programme always tried to provide appropriate water seal, siphon and SaTo pans to ensure hygienic latrine uses. In addition, different types of latrine technological options with related prices have been provided to the sanitation entrepreneurs so that community get access better services.

\subsubsection{Financial supports for entrepreneur}

Most of the entrepreneurs were financially vulnerable and considering their needs the programme supported twice 10,000 (ten thousand taka or about US $\$ 120.00$ only) interest free loan to 3,608 local entrepreneurs so that they could continue regular production. The financial support helped them a lot to establish the local entrepreneurs in WASH area.

\subsubsection{Strengthening supply chain}

Supply chain includes people, technology, organizations and resources involved in moving a product from producer to consumer. However, the supply chain for sanitation sector includes; distributors, wholesalers, local producers, masons and laborers. In the beginning, most of the hard-to-reach intervention area of the programme did not find out local entrepreneur and was a big supply chain gap. Therefore, the programme coordinated with best supplier from another area, so that; they could supply sanitary materials in convenient manner to increase sanitation coverage. The programme also helped them to find out branded raw materials i.e. good quality iron rings, cement, bricks, sands aggregate and mansion.

\subsubsection{Value chain development}

Value chain approach is a very recent interaction of BRAC WASH initiative to mitigate second generation challenge on sanitation especially for faecal sludge management. The term "Value Chain" was used by Michael Porter in his book "Competitive Advantage: Creating and Sustaining Superior Performance" (1985). The value chain analysis describes the activities the organization performs and links them to the organizations competitive position (Dagmar Recklies, 2001). It involves taking a macro look at the interactions and movements within an industry. Raw material inputs acquired 'upstream' are transferred into valuable goods 'downstream' chain mechanism. At each level in the chain, value- added processes increase the overall process of finished goods. In normal, commercial value-chains, decreasing non-value-added activities is extremely relevant in reducing the final selling price, such as excess movements, rework, labor, coordination, and waste 
Entrepreneur development management practices for sustainable service: case of BRAC Water,

(Cullen et. al. 2010). If poor consumers are required to pay a high prices offered for a toilet ring or pan, then they would have not the capacity to buy. So, the programme adopted this concept for competitive advantages.

\subsubsection{Advocacy and communication development}

The programme is disseminating behaviour change communication materials; delivered hygiene messages, arranged cluster meeting with different age groups, demonstrated hand washing practices at community and schools, arranged bi-monthly meeting with VWC members, presented poster to secondary school women groups, showed video documentary on WASH issues. The programme was also involved local institutions i.e. folk song groups, religious institutions and school to sensitise the community.

\subsubsection{Monitoring and quality assurance}

In the field, some individuals alleged that materials arrived at their homes already broken or broke even after they installed the toilet. Programme staff carried out regular visits and checks to ensure good quality materials. The programme also established an independent Monitoring and Quality Control (M\&QC) unit and this unit triangulated to ensure transparency and accountability of entrepreneur's services. If staff from this unit finds sub-standard materials being used; or delivered from any production centre, then they report it to the local regional manager to take immediate action. BRAC will not use suppliers who consistently deliver low quality products.

\section{BRAC wash's contribution on national sanitation target}

The BRAC WASH programme came at a time when substantial gains in the country were at risk. What had been thought to be 'safe' water coverage had fallen from $97 \%$ at the start of the 1990 s to $74 \%$ in 2004 , largely because of discovery of widespread arsenic contamination in 59 out of the 64 districts. Although the proportion of the population with access to hygienic latrines had risen from 20\% in 1990 to $39 \%$ in 2004, the poor and those living in difficult areas were largely left behind. Hygienic practices were erratic (BRAC WASH Programme report 2006-2015). The Programme has inspired millions of people in Bangladesh to install hygienic latrines, supporting poor and ultra-poor families with loans, grants and motivation. In all the 250 sub-districts taken together, 39.4 million people gained access to hygienic latrine during the progeamme period with combined effort of BRAC, government departments and other significant implementing agencies (BRAC WASH Programme report 2006-2015). At the beginning of this programme (2006), the national sanitation coverage was $39 \%$ (JMP 2006, UNICEF Bangladesh 2006, UNDP 2006, Kabir et al 2008), and in the WASH programme working areas sanitation coverage was even lower at $31.5 \%$ (BRAC WASH programme survey 2007). In 1990, the national open defecation status was $34 \%$ and that has now fallen to only $1 \%$ in Bangladesh. The present national coverage of improved sanitation is $61 \%$ (JMP/WHO/ UNICEF 2015), whereas, WASH working area sanitation coverage was $84 \%$ (MIS and QIS data of WASH, 2014). All latrine construction materials have been supplied through local entrepreneurs and they have made a huge contribution to stimulating demand and business opportunity for local social entrepreneurs.

\section{Conclusion}

To meet the national sanitation target in Bangladesh, BRAC WASH has developed sanitation entrepreneurs and linked them with communities. BRAC believes that entrepreneur development on WASH services cannot be effective, if it is imposed or adopted from outside and from inside. So, the community must be convinced. The necessary materials must accessible at the right price, in the right place and of the right quality which are significantly achieved. These development approaches could be applicable for other stakeholder who aims to same project in other developing countries.

\section{Reference}

[1]. Kabir, B., Kanti B., Rezaul K., Bodiuzzman,Rahman,M,. \&Mia,H.A..Contributions of Village WASH committee in breaking the cycle of unhygienic behaviours in rural Bangladesh. .South Asian Hygiene Practitioners workshop, Dhaka, Bangladesh.www.irc.nl. 2010, 1-5.

[2]. Akther, N., Kazi Faisal Bin Seraj, Syed Masud Ahmed, MA QuaiyumSarker, Ananta Z.Neelim, Tanveer M. Kamal and Tawhidul Islam. WASH Programme of BRAC:Towards Attaining the MDG,Targets: Baseline Findings, BRAC Research and Evaluation Division (RED).www.bracresearch.org. (2008), 34-55.

[3]. A Guide to the Development of on-site sanitation. World Health Organization, www.who.int /water_ sanitation_ health/.../onsitesan.pdf.1992. 1992, 17-34, 246

[4]. Erick Baetings and Ingeborg Krukkert. Sanitation Demand and Supply in Rural Bangladesh. Rapid assessment to identify supply chain constraints. A briefing paper of BRAC WASH II programme in Bangladesh.www.ircwash.org, 2014, 3-11.

[5]. Devine J.andKullmann, C, .Introductory Guide to Sanitation marketing, WSP Scaling Up Rural SanitationWAS World Bank. 2011: 18 .

[6]. Anthony Oyo. Creating Successful Private Sector Supply Chains. A resource guide for rural water supply and sanitation practitioners. Water and Sanitation Program, World Bank.1818 H Street, NW. Washington, DC 20433, USA.2002,

[7]. Seraj Kazi Faisal Bin (2008). Willingness to pay for improved sanitation. BRAC Research and Evaluation Division(RED). BRAC Centre, 75 Mohakhali, Dhaka-1212. Bangladesh. www.bracresearch.org.

[8]. Kabir Babar 2008; BRAC WASH Programme.South Asian Hygiene Practitioners workshop, 2010, Dhaka, Bangladesh.www.irc.nl.

DOI: $10.9790 / 487 X-180902159163 \quad$ www.iosrjournals.org $\quad 162 \mid$ Page


www.brac.net. 2008, .3-7.

[9]. BRAC. BRAC Water Sanitation and Hygiene Programme: Attaining the MDG Target on Water and Sanitation in Bangladesh (Project Proposal).www.brac.net, 2005. 15-33.

[10]. Annual Report (2010) Sanitation Gap, IRC International Water and Sanitation. Centre, Bezuidenhoutseweg 2, 2594 AV TheHauge, The Netherlands. www.irc.nl

[11]. Jenkins and Curtis. Achieving the good life: Why some people want latrines in rural Benin.Department of Civil and Environmental Engineering, University of California. And The Hygiene Centre. London School of Hygiene and Tropical Medicine, Keppl, St. London, WC1E 7HT. UK. 2005.

[12]. WHO and UNICEF . 2012.Progress on Sanitation and Drinking-Water 2010 Update.WHO / UNICEF Joint Monitoring Programme for Water Supply and Sanitation. http://www.unicef.org/media/files/JMP-2010Final.pdf.

[13]. [13] BRAC Water, Sanitation and Hygiene (WASH) programme: Nine years of scale and innovation in Bangladesh. Programme report 2006-2015. P 8-9. wash.brac.net. www.brac.net

[14]. WHO and UNICEF. Progress on Drinking Water and Sanitation 2015 Update. WHO / UNICEF Joint Monitoring Programme (JMP) for Water Supply and Sanitation.www.wssinfo.org. 2015, 14. 